\title{
Evolution of COVID-19 in Relation to Public Health Countermeasures in Morocco
}

\author{
Majda Sebbani ${ }^{1,2}{ }^{*}$, Latifa Adarmouch ${ }^{1,2}$, Adil Mansouri1,2, Mohamed Amine ${ }^{1,2}$ \\ ${ }^{1}$ Clinical Research Unit, Mohammed VI University Hospital, Marrakech, Morocco \\ ${ }^{2}$ Community Medicine and Public Health Department, Research Laboratory Bioscience and Health, School of Medicine, Cadi \\ Ayyad University, Marrakech, Morocco \\ Email: *dr.sebbani@gmail.com
}

How to cite this paper: Sebbani, M., Adarmouch, L., Mansouri, A. and Amine, M. (2020) Evolution of COVID-19 in Relation to Public Health Countermeasures in Morocco. Open Journal of Epidemiology, 10, 187-194.

https://doi.org/10.4236/ojepi.2020.102017

Received: April 15, 2020

Accepted: May 15, 2020

Published: May 18, 2020

Copyright (c) 2020 by author(s) and Scientific Research Publishing Inc. This work is licensed under the Creative Commons Attribution International License (CC BY 4.0).

http://creativecommons.org/licenses/by/4.0/

Open Access

\begin{abstract}
The new coronavirus, officially responsible for COVID-19, has spread rapidly internationally despite multiple countermeasures to limit its transmission. Morocco recorded his first case of COVID-19 on March 02, 2020. The main data on the pandemic and its evolution come from the Moroccan Ministry of Health. This paper aims to describe the evolution of the pandemic in Morocco and to highlight the different measures taken to stem its progression between March 02 to April 07, 2020. The measures were taken very early since the declaration of the first case in Morocco on March 2, 2020. After 5 weeks of the epidemic, the number of confirmed cases in Morocco reached 1184 including 90 deaths and 93 recoveries. The evolution of the curve seems to be slowed down compared to neighboring countries like Spain. The wearing of a mandatory mask was implemented on April 7 by the Ministry of Health as an additional measure to flatten the curve and allow the health system to effectively cope with the pandemic. The impact of this measure could be assessed by analyzing the evolution of the curve in the coming weeks. Sharing these results can serve as an example to other countries, especially for low-income countries, in their fight against the COVID-19.
\end{abstract}

\section{Keywords \\ COVID19, Morocco, Countermeasures}

\section{Introduction}

On December 31, 2019 a cluster of acute respiratory illness was reported from Wuhan, Hubei Province in China and later confirmed as novel coronavirus on January 7,2020 . This virus is a member of the same coronavirus family that caused the severe acute respiratory syndrome (SARS-CoV) reported in China in 
2003, and the Middle-East respiratory syndrome (MERS-CoV) reported in Saudi Arabia in 2012. The disease is now known as the COVID-19: the symptoms include cough, fever and shortness of breath [1] [2] [3]

The new coronavirus, officially responsible for COVID-19, has spread rapidly internationally despite multiple countermeasures to limit its transmission. The World Health Organization (WHO) has declared a state of international health emergency and since then, the health authorities are striving to establish procedures for rapid diagnosis and quarantine of patients as well as to speed up the research for effective therapeutics to counter the disease.

In the Eastern Mediterranean Region, as of February 15, 2020, eight cases were reported from the United Arab Emirates (UAE), of which six cases belong to two families and one case was imported from Egypt. The incident management system has been activated at the WHO Regional Office for the Eastern Mediterranean (WHO/EMRO) in Cairo, Egypt, in order to better coordinate and support the preparedness, readiness and response activities at the country and regional levels. WHO has categorized the risk of the COVID-19 outbreak globally as high, including the Eastern Mediterranean Region, because of the direct and indirect international travel from to and from China. Besides, many countries in the Region are experiencing or recovering from complex emergencies with fragile health systems [3].

At the moment of a massive increase in cases reported all over the world especially in Italy, France, and Spain, Morocco recorded his first case of COVID-19 on March 02, 2020. After that, from 11 to 13 of March a new case was reported each day [4]. Early detection of COVID-19 importation and prevention of onward transmission are crucial challenges to all countries at risk of importation from areas with active transmission. African Countries are vulnerable too: Algeria, Ethiopia, South Africa, and Nigeria were part of the 13 top priority countries identified by WHO based on their direct links and volume of travel to China. Few other discrepancies were observed (Morocco and Angola were estimated to be at moderate risk, but did not appear in WHO's 13 top priority list). This might be explained by different risk estimation approaches [5] [6].

Many studies have been published within different scientific disciplines with the intent to understand and then, control and prevent this pandemic. In Morocco, the main data on the pandemic and its evolution come from the Moroccan Ministry of Health. These data are updated daily on a dedicated website [7]. This paper aims to describe the evolution of the pandemic in Morocco and to highlight the different measures taken to stem its progression. Sharing experiences, especially for low-income countries, could help the authorities and stakeholders in similar countries to anticipate actions to be taken in the face of this new threat to international health.

\section{Methods}

We have followed the data published on the Ministry of Health website since the declaration of the first case in Morocco on March 2, 2020. The data concern the 
cases recorded every day including:

$>$ the number of new cases of COVID-19 confirmed by PCR;

the number of deaths;

the number of recovering cases.

The graphical presentations of the cumulative cases are presented by region

(12 administrative and health regions in Morocco). The evolution of the epidemic was confronted with the dates of introduction of countermeasures, namely:

$>$ closing schools, suspending unnecessary activities: sports, restaurants and cafés;

closing borders;

$>$ confinement and state of public health emergency;

$>$ compulsory wearing of a mask.

The data were supplemented by the WHO Coronavirus disease consultation (COVID-2019) situation reports, media and some accessible publications [4] [8] [9] [10].

This analysis concerns the situation between March 2 and April 7, 2020 (Date of the obligation to wear a mask).

\section{Results and Discussion}

Morocco tried hard to mitigate the spread of COVID-19 through a variety of strategies. The response against the Coronavirus was very stringent even in the initial phase [10]. Morocco is considered one of the countries which implemented drastic countermeasures early on considering the evolution of the outbreak (Table 1).

Almost half of the confirmed cases were notified in 3 out of the 12 administrative regions in Morocco (Figure 1). Of these cases, 30\% were recorded in Casablanca (the economic capital), $17.2 \%$ in Marrakech (the top touristiccity) and $15.7 \%$ in Rabat (the capital).

The measures were taken very early since the declaration of the first case in Morocco on March 2, 2020. After 5 weeks of the epidemic, the number of confirmed cases in Morocco reached 1184 including 90 deaths and 93 recoveries. The evolution of the curve seems to be slowed down (Figure 2).

For many countries, it is still difficult to predict the effects of specific major public health decisions, on the course of the COVID-19 pandemic. However, there are lessons to be learned from countries that have experienced an explosion of cases with a rapid transition to phase 3 such as Italy. Among the hypotheses is the failure to observe standard hygiene measures and confinement by the population accustomed to socialization and gatherings [11].

The measures taken made it possible, initially, to limit large gatherings, including face-to-face classes at schools or university establishments. This measure was accompanied in the same week by the broadcasting and dispensing of courses and distance learning via a Moroccan television channel and via electronic platforms for students and pupils. At this stage the number of cases recorded did not exceed 40 patients. Three days later, a state of health emergency 
Table 1. Description of coronavirus pandemic response in Morocco (public health countermeasures).

\begin{tabular}{|c|c|c|c|}
\hline Dates & Countermeasures & $\begin{array}{l}\text { Number of new } \\
\text { cases }\end{array}$ & $\begin{array}{c}\text { Cumulative } \\
\text { number of cases }\end{array}$ \\
\hline March 2 & A Moroccan citizen returning from Italy is tested positive & 1 & 1 \\
\hline 4 to 13 March & $\begin{array}{l}\text { Positive tests on } 4 \text { people coming from Italy, France, Spain, and Austria } \\
\text { - Suspension of flights from and to Italy, Spain, Algeria, France, Portugal, Germany, } \\
\text { Belgium, and the Netherlands. }\end{array}$ & 7 & 8 \\
\hline March 14 & $\begin{array}{l}\text { - Suspension of all cultural, educational, sportive and educational activities, and the } \\
\text { closure of cinemas, theatres, sports halls } \\
\text { - Ban of all gatherings attended by more than } 50 \text { people }\end{array}$ & 10 & 18 \\
\hline March 16 & $\begin{array}{l}\text { - Closure of preschool and nursery institutions, schools, vocational training, and } \\
\text { managerial training, and universities, including language centers and schools under the } \\
\text { responsibility of foreign missions and private institutions. } \\
\text { - Closure of public spaces (cafes, restaurants, cinemas and theatres, party halls, clubs and } \\
\text { sports halls, hammams, games rooms, and sports playgrounds) }\end{array}$ & 19 & 37 \\
\hline March 19 & $\begin{array}{l}\text { - Declaration of the health emergency state and restriction of traffic in Morocco starting } \\
\text { from Friday March } 20 \\
\text { - Each institution must keep only a few people able to guarantee the continuity of certain } \\
\text { fundamental activities such as e-learning } \\
\text { - Mobility of individuals outside their residence must be justified by an authorization } \\
\text { issued by the local authorities }\end{array}$ & 26 & 63 \\
\hline March 24 & Suspension of travel of all passengers transport vehicles outside cities & 107 & 170 \\
\hline April 7 & Obligation to wear a protective mask for anyone outside & 1014 & 1184 \\
\hline
\end{tabular}

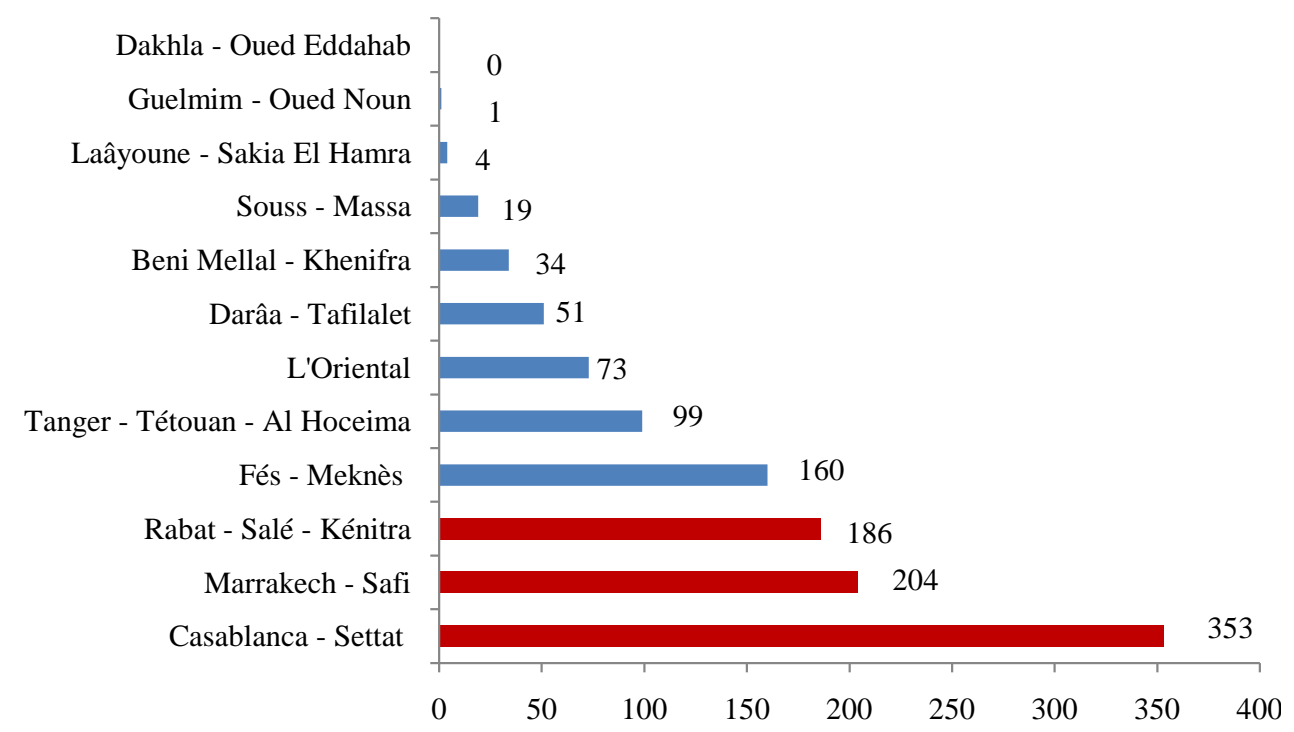

Figure 1. The distribution of 2020 COVID-19 cumulative confirmed cases in Morocco by Region (as of April 7, 2020).

was officially declared in Morocco (since March 20). Travel was authorized for work, seeking health-care or doing groceries and had to be justified and documented by competent authorities. The Moroccan population has entered a confinement phase with movement control as an additional measure to curb the spread of the virus. The reaction of fellow citizens was positive, especially given the 


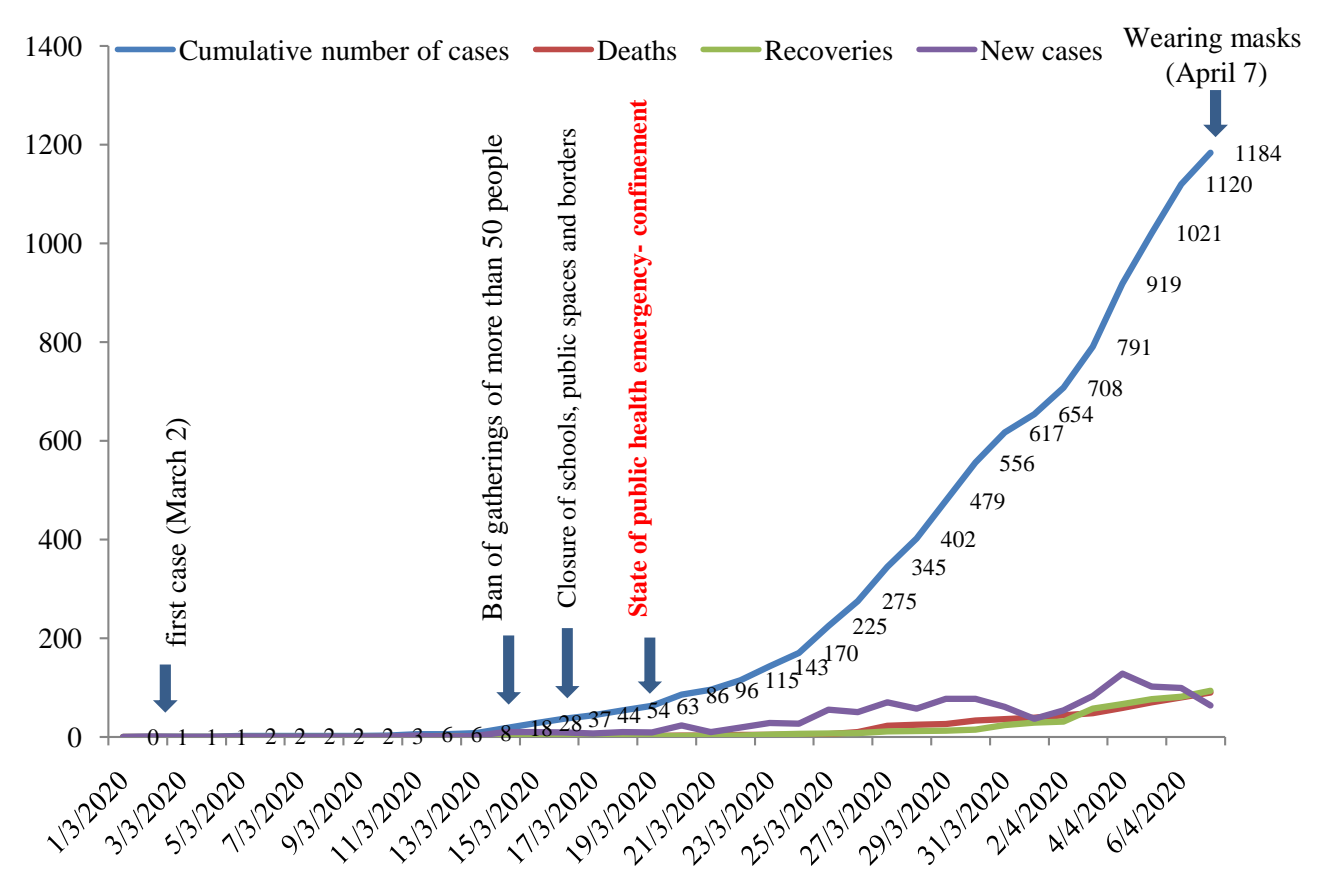

Figure 2. Coronavirus pandemic curve evolution in Morocco between March 2 and April 7 (2020).

great mobilization of civil society and the commitment of the state in the implementation of accompanying measures to succeed in the challenges imposed on the health, social and economic levels.

The support measures undertaken in Morocco have been manifold. Initiated by a call for national solidarity through the creation of an emergency fund dedicated to the fight against the pandemic and its socio-economic consequences. Thus financial aid in the form of compensation to the benefit of individuals who lost jobs and economically vulnerable groups was scheduled starting from April 7. Individuals and companies were offered the possibility to reschedule the payment of bank loans. Furthermore, tax statements procedure for small and medium-sized enterprises were postponed. This in addition to price controls in shops to avoid speculation and to ensure the availability of basic goods. The authorities also ensured that the confinement in the streets and neighborhoods was respected. In terms of health, the services offer has been strengthened thanks to the partnership between the public and private health sectors to ensure continuity and availability of care. Other measures have helped to avoid displacement of the population, such as the acceleration of the digitalization of several administrations by offering continuity of online services. Disinfection measures in public areas and administrations have strengthened the highly recommended personal hygiene measures communicated through the audiovisual media.

Morocco has thus anticipated in the implementation of several drastic measures to circumvent the spread of the virus from the start of the state of a publichealth emergency. The last was that of the compulsory wearing of the mask with the local production of masks at an affordable price (0.80 MAD) and their availability to the population in several points of sale including supermarkets 
and convenience stores. By the way, given the global shortage of protective masks, WHO recommends that the use of FFP2 masks and medical and surgical masks be reserved for healthcare professionals.

The wide use of masks by healthy people in the community setting is not supported by current evidence and carries uncertainties and potential risks especially regarding its management and appropriate use by people [12]. Morocco has encouraged the local production of masks intended to reinforce barrier gestures and has officially obliged it to be worn from April 7. This measure recommended by other countries, could significantly block the transmission of the virus in aerosols [13]. But in the absence of scientific evidence on its real effectiveness in reducing the risk of infection with SARS-Cov 2 [14] [15], it would be interesting to assess the evolution of the case curve within two weeks after its implementation in Morocco (Average incubation time of the virus). The approach of mask-wearing plus instant hand hygiene to slow the exponential spread of the virus was supposed by some authors and has been supported by the experiences of China, the Republic of Korea, and Japan, in fighting against COVID-19 [16].

\section{Conclusion}

Morocco, like other countries, is making unavoidable efforts to deal with the health risk of the new coronavirus. The measures were taken very early since the declaration of the first case in Morocco on March 2, 2020. After 5 weeks of the epidemic, the number of confirmed cases in Morocco reached 1184 including 90 deaths and 93 recoveries. The evolution of the curve seems to be slowed down compared to neighboring countries like Spain. The wearing of a mandatory mask was implemented on April 7 by the Ministry of Health as an additional measure to flatten the curve and allow the health system to effectively cope with the pandemic. The impact of this measure could be assessed by analyzing the evolution of the curve in the coming weeks. Sharing these results can serve as an example to other countries in their fight against the COVID-19.

\section{Acknowledgements}

The authors want to acknowledge the Moroccan government for its efforts and the population for their positive reaction.

Big thanks to all health-care workers for their commitment.

\section{Conflicts of Interest}

The authors declare no conflicts of interest regarding the publication of this paper.

\section{References}

[1] World Health Organization (WHO) (2020) Novel Coronavirus (2019-nCoV). Situation Report 1, 21 January.

https://www.who.int/docs/default-source/coronaviruse/situation-reports/2 
0200121-sitrep-1-2019-ncov.pdf?sfvrsn=20a99c10 4

[2] Zhou, P., Yang, X.-L., Wang, X.-G., Hu, B., Zhang, L., Zhang, W., et al. (2020) A Pneumonia Outbreak Associated with a New Coronavirus of Probable Bat Origin. Nature, 579, 270-273.

[3] WHO Regional Office for the Eastern Mediterranean, Al-Mandhari, A., Samhouri, D., Abubakar, A. and Brennan, R. (2020) Coronavirus Disease 2019 Outbreak: Preparedness and Readiness of Countries in the Eastern Mediterranean Region. Eastern Mediterranean Health Journal, 26, 136-137.

https://doi.org/10.26719/2020.26.2.136

[4] Ait Addi, R., Benksim, A., Amine, M. and Cherkaoui, M. (2020) COVID-19 Outbreak and Perspective in Morocco. Electronic Journal of General Medicine, 17, em204.

https://doi.org/10.29333/ejgm/7857

[5] WHO Ramps Up Preparedness for Novel Coronavirus in the African Region. WHO Regional Office for Africa.

https://www.afro.who.int/news/who-ramps-preparedness-novel-coronaviru s-african-region

[6] Gilbert, M., Pullano, G., Pinotti, F., Valdano, E., Poletto, C., Boëlle, P.-Y., et al. (2020) Preparedness and Vulnerability of African Countries against Importations of COVID-19: A Modelling Study. The Lancet, 395, 871-877.

https://doi.org/10.1016/S0140-6736(20)30411-6

[7] The Official Moroccan Portal Coronavirus. http://www.covidmaroc.ma/Pages/AccueilAR.aspx

[8] Novel Coronavirus (2019-nCoV) Situation Reports. https://www.who.int/emergencies/diseases/novel-coronavirus-2019/situatio n-reports

[9] Medias24-Site d'information. https://medias24.com/coronavirus.html

[10] Maneesh, P. and El Alaoui, A. (2020) How Countries of South Mitigate COVID-19: Models of Morocco and Kerala, India. https://ssrn.com/abstract $=3567898$ https://doi.org/10.2139/ssrn.3567898

[11] Boccia, S., Ricciardi, W. and Ioannidis, J.P.A. (2020) What Other Countries Can Learn From Italy During the COVID-19 Pandemic. JAMA Internal Medicine. https://doi.org/10.1001/jamainternmed.2020.1447

[12] Advice on the Use of Masks in the Community, during Home Care and in Healthcare Settings in the Context of the Novel Coronavirus (COVID-19) Outbreak. https://www.who.int/publications-detail/advice-on-the-use-of-masks-in-th e-community-during-home-care-and-in-healthcare-settings-in-the-context -of-the-novel-coronavirus-(2019-ncov)-outbreak

[13] Zhou, Z.-G., Yue, D.-S., Mu, C.-L. and Zhang, L. (2020) Mask Is the Possible Key for Self-Isolation in COVID-19 Pandemic. Journal of Medical Virology. https://doi.org/10.1002/jmv.25846

[14] Mahase, E. (2020) Covid-19: What Is the Evidence for Cloth Masks? BMJ, 369, m1422. https://doi.org/10.1136/bmj.m1422

[15] Bae, S., Kim, M.-C., Kim, J.Y., Cha, H.-H., Lim, J.S., Jung, J., et al. (2020) Effectiveness of Surgical and Cotton Masks in Blocking SARS-CoV-2: A Controlled Comparison in 4 Patients. Annals of Internal Medicine. 
https://doi.org/10.7326/M20-1342

[16] Ma, Q.-X., Shan, H., Zhang, H.-L., Li, G.-M., Yang, R.-M. and Chen, J.-M. (2020) Potential Utilities of Mask-Wearing and Instant Hand Hygiene for Fighting SARS-CoV-2. Journal of Medical Virology. https://doi.org/10.1002/jmv.25805 